\title{
Engaging students in practice learning through a model of group supervision
}

\section{Jayne Howie $^{1}$ and Jill MacSporran ${ }^{2}$}

Summary: Group learning is established as a productive way to educate and socialise social work students. The University of the West of Scotland has developed a small scale practice learning centre and a model of group supervision, to assist our students in assessed practice. This paper examines this method of learning, the students' experience and their perceptions.

Our evaluation confirms that when group management processes are employed and students are involved in focused activities, this is a productive method of learning. Group supervision encourages students to think analytically, developing competence and confidence, and provides opportunity for an exchange of ideas which develop reflective skills.

Central to success is a programme which fits with the students' stage of learning and practice teachers who attend to the learning environment, group process and dynamics. Providing these characteristics are in place and when used along with individual supervision, group supervision can offer students a richer learning environment.

Key words: Practice learning, group supervision, focused activities

1. Lecturer in Social Work, University of the West of Scotland

2. Practice Learning Development Officer, University of the West of Scotland

Address for Correspondence: University of the West of Scotland, Paisley Campus, High Street, Paisley PA1 2BE. Jayne.howie@uws.ac.uk

Date of publication: 31st March 2011

Acknowledgements: The authors wish to thank Anne Ritchie and Irene Goodheir for their support, guidance and contribution to early drafts of this article. Also many thanks to Lynne Poole and the reviewers of the article for supportive direction.

27 J. of Practice Teaching \& Learning 10(1) 2010, pp.27-44. DOI: 10.1921/ 146066910X570276. @ w\&bb 


\section{Introduction}

In social work training creating a conducive learning environment in practice learning is core to 'developing competent, confident, professionals, able to undertake the role in an increasingly complex and changing world' (Scottish Executive, 2004:1). Consequently, the learning environment shapes students' perceptions and develops lasting attitudes toward their profession (Mezirow, 1981; Brookfield, 1987). The centrality of the learning environment was also highlighted by the Laming Inquiry, which questioned the way social workers are educated and how practice is managed (Lord Laming's Progress Report, 2009).The Taskforce report and the Children and Families Select Committee report on social work training highlight the need to review how social workers are educated (Building a safe, confident future- Social Work Task Force, 2009 and Children, Schools and Families Committee-2009). Amongst other things, the Inquiry and these reports emphasised that integrated practice and constructive supervision were essential in producing individual and organisational learning, and that trained and experienced staff were essential to adequate service provision. Organisations were urged to consider the place of informal supervision, group supervision and team work in the role in service delivery. Accordingly, social work educators were encouraged to cultivate practitioners who kept learning continual to aid their own development and attain both organisational improvement and effective outcomes for service users.

The foregoing reports, along with the $21^{\text {st }}$ Century Social Work Review, Changing Lives (2006), fuelled debates about what we teach social work students and how they learn, as educators, employers and practice teachers can have differing ideas about the learning environment, the nature of learning opportunities and what is taught when. On social work programmes practice learning is the vehicle for transferring and applying knowledge to ensure students are sufficiently equipped to practice. There are a variety of models offering direction on how to integrate the required practice skills with teaching (Brookfield, 1987; Kolb, 1982). Approaches that facilitate models of adult learning are more likely to support the student's ability to transfer learning and integrate this with practice. Subsequently, educators have employed a range of strategies to merge the line between classroom and practice learning and Higher Education Institutes (HEIs) have worked to increase the 
'quality, quantity and diversity of practice learning opportunities' (Scottish Executive, 2004:1).

In response to these demands and to continuing difficulties in securing enough practice learning opportunities, the University of the West of Scotland (UWS) strove to create innovative ways to provide practice experiences for our students. UWS piloted a University-based practice learning centre with the intention to review and evaluate the experience before developing the model of learning for future cohorts. The development of our practice learning centre was based around a blended model of peer learning, using both individual and group supervision. The aim of this paper is to evaluate the effectiveness of the model of group supervision used and to provide some insight into the process and the experiences of those involved, specifically the students.

\section{The Practice Learning Centre}

The practice learning centre built on existing partnerships between the University and agencies to allow us to continue to provide productive learning opportunities, supported by experienced workers. We approached a number of agencies within the voluntary and statutory sector, inviting them to work with us to develop practice learning settings. The final selection of placements included four from the statutory sector and four from the voluntary sector. We developed a partnership agreement with agencies and practice teachers to clarify issues such as accountability for the students' practice and included this within our standard practice learning agreements. As the practice teachers were not employees of the agencies this clarified the roles and responsibilities of each member of the training team, paying close attention to accountability for the students' work.

\section{Practice teachers and link workers}

We contracted with three experienced practice teachers who took on the role of 'independent' practice teacher, meaning that they had self-employed status and were paid a daily rate per placement day. Given that they were contracted to the University, accountability was

29 J. of Practice Teaching \& Learning 10(1) 2010, pp.27-44. DOI: 10.1921/ 146066910X570276. @ w\&bb 
held by the education institute and the placement agreement provided this clarity. Each setting identified an experienced worker to take on the link worker role, to support the student and provide ongoing feedback to the practice teacher. As the link worker's role was pivotal in the learning process, it was important they understood the purpose and role of group supervision in the student's learning, therefore link workers were provided with training from the University and supported in developing learning opportunities.

\section{The students}

Students were selected and matched to the eight settings in the normal way, taking into account geographical location, previous experience and individual learning needs. We worked with final year students on their 90 day placement, our rationale being that they were already known to us and their learning needs were clear. This meant matching to settings was more straightforward and more likely to meet their learning needs. A staff member from the University had responsibility for negotiating and developing individual learning opportunities prior to placements commencing. Students on the programme had the support of a personal tutor and they were briefed about the 'blended' supervision model to ensure provision of additional support to students. It was anticipated, for example, that some students might struggle with being in a group and tutors would be able to help students move through the stages of group development.

\section{The influential theories}

According to Kadushin and Harkness (2002), the functions of supervision are administrative, educational and supportive. These functions are necessary for effective supervision and the development of the learner. In practice learning it involves assessment and feedback on competence, resulting in supervision being a powerful transformational learning tool.

Students are traditionally supervised on a one to one basis. However, where practice teachers are supervising more than one student they may,

30 J. of Practice Teaching \& Learning 10(1) 2010, pp.27-44. DOI: 10.1921/ 146066910X570276. @ w\&b 
on occasion, involve them in periods of group supervision. Bamford and McVicker (1999) highlighted the benefits of adopting this approach, claiming that it equips individuals with improved communication skills, partnership working skills and enables the development of critical reflection. According to Bernard and Goodyear (1998), group supervision offers the opportunity for practitioners to expand their learning and enhances coping skills, particularly when they practice in isolation. Although the practice teacher is still responsible for the functions of education, support and management, in a group supervision environment they must also manage the group work process and group dynamics. Kadushin and Harkness (2002) insist that managing this process is crucial to creating a productive environment, and Bogo et al (2004:211) claim that structuring the process 'as well as challenging group dynamics in a supportive manner' is significant to student learning.

Through our experiences as practitioners, practice teachers and educators we understand that learning is about relationships between people. As Walker et al notes (2008:56) 'It is not just what goes on in people's heads but (learning) takes place through the involvement of the individual in the wider community of their practice'. Thus learning is not just something that occurs in the mind, it is shaped by context, culture and the influence of the 'learning tools' such as educators, practice teachers and link workers. Mezirow (1981) provides a comprehensive outline of how we can identify and manage these learning tools through a process of transformational learning. He claims evoking a transformation in learners requires three key characteristics to be present: the centrality of the experience; critical reflection and; rational discourse (Mezirow, 2000). Relating this to students in a group supervision environment requires the placement to offer appropriate learning experiences and for the practice teacher to prompt the student into reflecting on their experiences through a focused discussion in supervision. This is because experience alone does not necessarily produce reflection. Students must engage in experiences and in discussion with those significant in the learning process in order to change their perceptions. Practice teachers must facilitate self awareness and reflection by helping students to become aware that their perspectives have shifted and through discussion in supervision, prompt reflection in order that students can transfer this learning into practice. In a group environment this is more likely to happen when the practice teacher uses the forum to create opportunities for students to reflect by listening to the views

31 J. of Practice Teaching \& Learning 10(1) 2010, pp.27-44. DOI: 10.1921/ 146066910X570276. @ wEbb 
of others. Consequently, learning in groups becomes another powerful transformational learning tool.

Kolb (1984) and Schon (1987) maintain that through learning from each other a sense of self reflection and peer learning is more likely. By using a theme or a case study approach to generate discussion, the peer group will bring a variety of perspectives and knowledge which in itself prompts reflective learning. This suggests that group environments and group dynamics are a powerful medium which can influence self awareness and facilitate changes in the students. Kadushin and Harkness, (2002); Doel, (2006) and Lindsay (2008) claim that group supervision can produce an increase in knowledge and promote a sense of the professional self, especially when peers see each other demonstrating the connection and application of theory in their discussion. It can build confidence for students by reducing their isolation in practice learning through the comparing and contrasting of experiences and thus significantly develop communication skills.

Kadushin and Harkness (2002:399) maintain, 'group supervision must be directed towards the common needs' of the students at a specific level of learning and 'the particular needs of none'. Consequently, in order to address individual needs, one to one time with the practice teacher is necessary. They urge caution when using this model as the relationships between group members and those directing the learning is significant in determining how the group will function. There is a fine balance to be had between letting the group be self controlling and of controlling the members (Kadushin and Harkness, 2002). Participants need to work with each other in a productive way and not get caught up in competitiveness or negative behaviours in order to bring about learning and shifts in attitudes and perspectives.

When designing our model we acknowledged that group environments could offer learners a forum where they could discuss experiences and use discussions to learn. We took on board the idea that a productive group enabled learners to learn from each other and a community of learners could be created which engaged students in the learning process. If learners are already a homogeneous group - for example, at the same stage of learning and working towards the same learning outcomes - then the group was more likely to be productive. In order to ensure that learning in this forum would be effective for students we also noted that attention to the group work process was essential. As Behroozi, (1993) indicates this process would involve

32 J. of Practice Teaching \& Learning 10(1) 2010, pp.27-44. DOI: 10.1921/ 146066910X570276. @ w\&bb 
students and practice teachers in the following phases. First, the preparation or orientation stage where individuals come together to set out the learning environment and the principles involved in this method of learning. At this stage students would gain insight into who was in the group and the tasks involved in their learning. As the group becomes established a period of dissatisfaction will arise resulting in conflict, tension and apprehension about this method of learning. If students are not able to work through this stage towards a productive resolution and way of working, then it is unlikely that any learning or change will take place which will enable the students to reach the production stage, that is, an effective way of working and learning together before termination. Consequently, the group must be appropriately planned and attention given to the group work process employed. Thus those involved in planning and directing group supervision needed a dual focus of enabling learning while attending to group needs.

\section{Our model}

The foregoing theories emphasised the significance of linking practice experiences with purposeful discussions in supervision to prompt reflective learning. They were influential in developing our model and consequently we used a blend of individual and group supervision. The students developing skills and reflective abilities are linked with the focused experiences they have in practice learning and pivotal to this is the reflexive dialogue and the relationship they have with practice teachers and their peers in group supervision. In maximising skills and resources, students came together on alternate weeks for group supervision. All Practice teachers contributed to the process and used sessions as formative assessment opportunities. These were not intended to be a substitute for individual supervision as students continued to be supervised individually by practice teachers. Rather, it was anticipated that the two methods of supervision would provide a richer and more creative learning environment.

The model of supervision was that students met once every five placement days for either group or individual supervision. Out of a total of eighteen supervision sessions students were offered eight group sessions, all of which were themed. The group was further divided into

33 J. of Practice Teaching \& Learning 10(1) 2010, pp.27-44. DOI: 10.1921/ 146066910X570276. ๑ wE-b 
sub groups of four and in addition to the practice teacher, each group had a member of staff from the University assigned to facilitate the running of the group. Their job was not to assess students' competence.

Themes were used to meet the needs of the group which reflected their stage of learning. There was an expectation that students would come to each session prepared to deliver a short presentation on the theme, based on their own experiences drawn from practice settings. They also provided a page of bullet points or notes used for the presentation. One theme for this group was risk assessment and students were prompted to contribute to the discussion by offering suggestions as to possible alternative approaches. Practice teachers worked to ensure students had respect for each other and a willingness to engage in discussion. They encouraged students to work as a team by being conscientious and open to the suggestions and ideas of others. Students were invited to become involved in their learning through participating in specific tasks while peers provided support. We expected that group discussion would aid peer knowledge development and enhance learning by focussing and directing learning in the manner suggested by Mezirow (2000).

Practice teachers channelled a dialogue around the themes and through peer discussion students were helped to apply their knowledge and integrate concepts into their specific placements. Practice teachers provided feedback to each student using sessions as a means of formative assessment and encouraged discussion to ensure that students could share their feelings and emotions regarding the issues highlighted. This enabled us to connect to the other characteristics which Mezirow (2000) claims prompts transformation, namely rational discourse and critical reflection. This means that the role of the practice teacher is significant in enabling and facilitating the development of self awareness and reflection in the student.

Mezirow's theory claims learners need the opportunity to have a focused discussion. A rational discourse with the themes emerging from practice is required to prompt critical reflection and this in turn enables the learner to re-examine their perspectives. According to Mezirow it is this that leads to the desired transformation required by the profession. Mezirow claims learners will pass through different stages in order to change their perspectives and achieve the transformation and desired learning aimed for by the educator. In order to achieve this the educator and the practice teacher must take responsibility for focusing and directing the students' learning.

34 J. of Practice Teaching \& Learning 10(1) 2010, pp.27-44. DOI: 10.1921/ 146066910X570276. @ w\&b 
In practice learning, supervision has the added challenge of supporting students while assessing them and in group supervision this is more complex due to members' individual needs. Consequently, the stages of group development are significant to the success of the students' learning and when designing our model it was essential to consider these (Behroozi ,1993, cited in Preston -Shoot, 2007). Group dynamics are more powerful when working with involuntary clients and our students could be seen as such as they had little choice in participating in the pilot; they automatically became members if their placement setting was part of the pilot. As noted above, Behroozi (1993) identifies five stages in group development: orientation, where members exhibit eagerness and ambivalence; dissatisfaction which includes rivalry and curiosity; followed by resolution; production and; termination. Thus it was important to use practice teachers who were familiar with these phases in order to manage the group effectively as it moved through them.

\section{Methodology}

The majority of the literature surrounding group supervision focuses on the benefits and group process. However, our small scale evaluation specifically aimed to investigate the students' feelings and perceptions regarding group supervision in order to understand more about the process. A qualitative approach was employed using interviews, focus groups and questionnaires. Qualitative research usually involves small samples and as there were eight students, eight link workers, three practice teachers and five tutors, this approach seemed to fit. Using small samples can be misleading and could mean the findings may not be representative of the student population as a whole. However, feedback from the other key players in the practice learning experience would allow for the triangulation of the data (Robson, 2000; Sarantakos, 2005). An interpretive epistemology was used as it fitted with our objectives of understanding the meaning of group supervision from the students' perspective in order to bring user knowledge into the HEI.

Prior to commencing the evaluation we gained permission from the Ethics Committee and from the participants. As the evaluators were involved in facilitating the running of the practice learning centre there were a number of ethical issues to consider when planning. Given our

35 J. of Practice Teaching \& Learning 10(1) 2010, pp.27-44. DOI: 10.1921/ 146066910X570276. ๑ wE-b 
positions within the University and our involvement in the practice learning centre, for example, the issues of power and authority could create a conflict of interests. The writers reflected on the researcher -respondent relationship in order to ensure anonymity, confidentiality and sensitivity, and we were clear with individuals about the purpose of the evaluation and how information would be used.

Initially the questions were tested on another group of students who were currently in group supervision while on practice learning with another University. This allowed the writers to gain immediate feedback about the drafting of questions and develop questions that would obtain the information we required. We formulated open questions in a diamond format for all those involved. Sarantakos (2005) maintains that written questionnaires reduce 'interviewer bias' because there is uniform question presentation and, used with other methods, they can aid triangulation.

We advised participants of the evaluation by letter, sent out after the students had completed all the practice learning days. Included were a questionnaire with instructions which they were asked to complete anonymously, and a request to take part in a group activity. Tutors and link workers were asked to complete a postal questionnaire and practice teachers were given one to one interviews where the questionnaire was completed alongside the evaluator. A total of 24 questionnaires were sent to those involved and 21 were returned.

In addition, a focus group was used as a tool to further assess user experiences with a view to eliciting users' reactions and enabling evaluators to observe some of the group dynamics at work. In order to be clear about the purpose of the focus group and set the scene for evaluation we used a snakes and ladders approach for reflection to allow the student group to visually represent the highs and lows of the experience This involved the student group creating a snakes and ladders board using numbers 1-100 and then depicting the highs and lows of their experiences by using snakes to represent the lows and ladders to represent the highs. Further information about this approach can be found on the website (http://www.northumbria.ac.uk ).

All students participated in the focus group and they completed the exercises without the evaluators present. Subsequent group discussions enabled the researchers to obtain further information about the students' experiences and their learning. This meant that no student was individually identified and ensured anonymity in their feedback.

36 J. of Practice Teaching \& Learning 10(1) 2010, pp.27-44. DOI: 10.1921/ 146066910X570276. @ wEb 
The session was free-flowing and relatively unstructured, although both facilitators followed a pre-planned script and goals for the information to be gathered (Sarantakos, 2005).

Practice teachers were interviewed individually, allowing them the opportunity to discuss their experiences in depth. Both the interviews and the questionnaires used open questions to allow participants to express their views and beliefs and gather the perceptions of those involved. However, we also used some closed questions to measure specific aspects of the experiences, for example learning opportunities and outcomes. All methods were designed to be complementary and the variety allowed a richer source of information to be obtained, while triangulation ensured integrity (Robson, 2000; Whittaker, 2009).The data was coded by the authors and the senior lecturer and data examined to glean findings.

\section{Students' feedback and outcomes}

Students confirmed that group supervision was a positive experience and they listed the following benefits:

- It focused and directed their learning

- It provided a challenging but valuable learning environment

- It assisted students in reflective thinking

- It assisted students in writing practice assignments

- The peer environment was a significant factor in their learning and development

- Discussions aided their understanding and application of theory

- It reduced feelings of isolation in practice learning

Feedback from the students confirmed that the themed sessions made a positive contribution to learning, with many claiming to be able to talk with more confidence about their practice. One respondent summed up their experience of group supervision as follows: 'members shared their perspectives, experiences and criticisms to enable individuals to develop their understanding and knowledge of their practice and help overcome dilemmas and concerns they faced'.

All student respondents felt that the group forum empowered them

37 J. of Practice Teaching \& Learning 10(1) 2010, pp.27-44. DOI: 10.1921/ 146066910X570276. ๑ wE-b 
as discussions generated ideas which they then applied to their practice. Students maintained that it was positive that they were at the same level of experience as one another as it felt safer and reduced isolation. They indicated that exposure to other students' perspectives was a key factor which aided learning, particularly for weaker students.

Six out of the eight respondents reported group supervision was a culture shock and felt it was more of a challenging learning environment than they were used to but one which was valuable. Most had only experienced individual supervision, with some students having a poor experience of it and this influenced their views about supervision in general. One respondent stated: 'my only experience of supervision was on a one to one, I did not want to be part of group supervision and was negative about it... in comparison I have to say I've had a beneficial experience and one which stretched me and aided my learning'. Students said that they did not realise the benefits of group supervision until the midway point of the placement, when they felt able to write their interim practice reports with greater clarity. One respondent wrote: 'I enjoyed being part of the group.... I feel I would not have been as well prepared for completing my reports without group supervision sessions as I learned a lot from my fellow students' contributions.'

The feedback confirmed that group supervision enabled the students to develop a stronger connection to the theory and knowledge base, as students reported that they felt more confident talking about practice in other forums, such as resource meetings or Children's Hearings. Overall, most believed the experience allowed them to work in a more competent way in a social work setting and this in itself was empowering.

\section{Practice teachers' feedback}

All practice teachers felt that group supervision aided the students' learning and developed competence. One practice teacher said: 'as long as the students are actively engaged through discussion, having access to a variety of settings widens the student's horizon. They promoted learning in each other and you could see them comparing their practice and approaches'. They claimed that the group environment provided a different forum for evidence gathering as they saw their students in a different light.

38 J. of Practice Teaching \& Learning 10(1) 2010, pp.27-44. DOI: 10.1921/ 146066910X570276. ๑ w\&bb 
Hence it aided them in student assessment and they referred to this evidence in their reports.

All reported that students developed increased self awareness and presentation skills and this enabled them to gain deeper insight into their use of self. All claimed students grew in professional competence and talked with more clarity about their practice. One practice teacher informed us: 'students appeared to become more comfortable sharing and presenting their work and talking about it with each other, the themes provided a structure for the group and was a positive factor in promoting student learning and their understanding of role and task across settings'. Utilising the group environment to gather evidence of competence was a new experience and took time to adjust to. One practice teacher did not feel comfortable in the group environment as working in a group situation was new to them and they found it difficult to attend to all of the students. One Practice teacher said: 'some thought could be given to promoting consistency and links between group sessions and practice teachers should provide some basic feedback to each other'. In effect the practice teachers felt that they needed to work hard at becoming a team and had to be consistent in their approach as they had not worked together before.

All practice teachers maintained that the experience provided them with deeper insight into the way different individuals learn and respond to feedback. In the light of this the amount of feedback was identified as a difficult question as one individual reported: 'the balance of just how much feedback to give was hard work at times as we had to be careful not to monopolise the discussion in order to allow students to participate and to learn'.

\section{The experience}

Our evaluation highlighted the significance of the group process itself within our model of supervision and we have evaluated the process and analysed the findings with reference to the specific stages of group development. At the preparation and orientation stage, students and practice teachers came together to agree ground rules and boundaries which embraced a value base of inclusion, respect and commitment. Most members were expressing enthusiasm and commitment and reported that they felt well prepared and were provided with sufficient

39 J. of Practice Teaching \& Learning 10(1) 2010, pp.27-44. DOI: 10.1921/ 146066910X570276. @ wEb 
information about the practice learning centre. However, some members were unsure about why they had been selected and we did not anticipate an unhelpful group dynamic where other students (who were not involved in the pilot) had suggested the purpose was to help students who were having difficulties on the programme. While this was in no way true, it led to selected students feeling anxious and suspicious about the process. Students also felt group supervision would mean additional work and were naturally ambivalent about that.

After the first few sessions it became clear some students had entered the dissatisfaction stage and were showing unhappiness with group supervision. They were nervous and anxious about presentations and felt they were being asked to do additional work in comparison with other students. At this point students could not see the benefits of group supervision in terms of peer learning and shared feedback. Consequently, as Benson (2010:87) notes, the practice teachers and the facilitators had to take time to re-create the learning environment: 'The first task of the group supervisor is to create a predictable and consistent space and promote a learning culture in which supervision can take place'.

It was necessary to clarify and reiterate the aims and purpose of group supervision and allow students to discuss their fears and concerns in relation to this method of learning before they could move forward to reach a resolution. The role and experience of the practice teachers was crucial at this time as they had to pay attention to the emotional well being of the group members. Students will not be sufficiently engaged and motivated or willing to disclose their learning needs and anxieties if this does not happen (Benson, 2010). We anticipated that if the right learning environment was not created there was a danger students could fail to connect to the learning process. Consequently, attention to group processes and dynamics was essential and the practice teachers' experience and ability to facilitate these was fundamental. As Kadushin and Harkness (2002) maintain, practice teachers have to be skilled in maintaining group cohesion and monitoring interactions, so that the process is productive rather than the cause of conflict. Consequently, the development of group work skills appear to be an essential component in group supervision, as they equip practice teachers with more confidence and a greater ability to create the optimum learning environment.

The data suggests that students felt they were able to positively move forward once they had a chance to discuss and resolve some of their

40 J. of Practice Teaching \& Learning 10(1) 2010, pp.27-44. DOI: 10.1921/ 146066910X570276. @ w\&bb 
fears and anxieties. It appeared that at the orientation and dissatisfaction stages their learning cycle was blocked (Kolb, 1984). Students needed to work through the resolution stage before they could move forward into the production phase. This involved members taking on agreed responsibilities and coming prepared to each session willing to present their work and give and receive feedback. Initially students found this threatening but, by agreeing ground rules and being able to develop a mutual trust within the group, they were able to achieve a more meaningful and richer learning environment.

Up until the midway point all of those involved in the experience found themselves within a constrained learning environment. It was only after the midway point that the students moved into the production stage where they performed effectively with defined roles. In fact at this stage it could be said the group had transformed into a team and learning had begun. This was reinforced by both students and practice teachers in their feedback and highlights the significance of the group process. While students were unable to articulate this during the process, in evaluation they told us that they felt group supervision had been worthwhile and was more meaningful by the end of the process than it had felt at the beginning.

\section{Limitations to the model of group supervision}

Our findings established the importance of taking responsibility for the learning environment, concurring with the literature on group supervision and learning in groups. Consequently, in creating peer learning environments practice teachers must be able to work as a team, building up the trust and confidence of the group. When students are resistant or fearful of this form of learning, it is extremely difficult to move them through the disorientation phase and into the edge of learning. It takes a skilled practice teacher to encourage students not to see group supervision as extra work and help them transfer their learning to the specifics of their placement. The relationship between the student and practice teacher is significant within group supervision confirming Mezirow's claim that providing there is opportunity for ongoing discussion with those focusing the learning and this is connected to practice, then a transformation of skills and knowledge will occur. It seems then that the success of this model depends on the

41 J. of Practice Teaching \& Learning 10(1) 2010, pp.27-44. DOI: 10.1921/ 146066910X570276. @ w\&bb 
practice teachers' communication skills and ability to attend to the group process, while simultaneously assessing competence and providing feedback. When these aspects are in place the benefits to the students are significant, therefore it is essential to address issues about group process in the planning stages.

Feedback from both students and practice teachers confirmed that consideration had to be given to the practice teachers' group work skills, students having more opportunities for critical incident analyses and the issue of students having to write presentation notes for the group session. In the following academic year, we amended the model and used practice teachers who were experienced in group supervision and who understood group learning, thus there was no need for University facilitators as the practice teachers were confident in running the group. In response to the queries about the amount of written work, we produced materials that allowed them to depict the key points of discussion in a diagrammatic form and introduced more opportunities for critical incident analysis. In the briefing for students we paid more attention to the orientation stage, ensuring we explained the rationale for selection to the group with more clarity.

\section{Conclusion}

Engaging students in supervision in a practice learning context is a complex process. Our evaluation examined the process of learning for the students involved in our model of group supervision and established this method of learning can be productive when students connect with the learning process and both students and practice teachers develop a relationship which enables them to work towards their learning outcomes. The data confirmed that providing group supervision creates a conducive learning environment; it offers opportunities to develop self awareness and critical reflection which can assist students to transfer this learning into the skills needed for competent practice. A group programme which fits with the particular stage of learning for the student can encourage the student to examine their perspectives and consider how they may apply their knowledge to practice situations. The use of peer feedback prompts students to develop a stronger self awareness, building up a confident and competent persona. It is

42 J. of Practice Teaching \& Learning 10(1) 2010, pp.27-44. DOI: 10.1921/ 146066910X570276. @ wEbb 
effective in linking students into the reflexive cycle outlined by Adams et al (2009) where we engage with the context, the self, the experience and the dilemmas. Central to prompting reflexive learning is the role of the practice teacher and the focused discourse they enter into with the students.

Significant to the success of the model is the ability to attend to the group process and manage group dynamics. Thus managing the learning environment is essential to the students' professional development. Ultimately, we have integrated our findings into provision for the current cohort in the practice learning centre and will continue to evaluate the model's effectiveness to determine the fuller benefits of this method of learning and, in due course, whether this approach works and improves outcomes for service users and organisations.

\section{References}

Adams, R. Dominelli, L, and Payne, M. (2009) Critical Practice in Social Work (2nd ed.), Basingstoke: Plagrave MacMillan

Bamford, D. and McVicker, H. (1999) Group approaches within social work education and training. Issues in Social Work Education 19, 35-54

Behroozi, C. (1993). A Model for social work with involuntary applicants .groups. Social Work with Groups Journal, 15, 223-238

Benson, J (2010) Working More Creatively with Groups. (3rd ed.). London: Routledge

Bernard, J.M and Goodyear, R.K. (1998) Fundamentals of clinical supervision. Needham Heights, MA: Allyn \& Bacon

Bogo, M, Globerman, J., and Sussman, T. (2004) Field instructor competence in group supervision. Journal of Teaching in Social Work 24,199-216

Brookfield, S. D. (1987) Developing Critical Thinkers. San Francisco: Jossey-Bass

Department for Educations (2009) Building a Safe, Confident Future: The final report of the Social Work Task Force. Runcorn: Department for Education

Doel, M (2006) Using Groupwork. London: Routledge

Government Publications (2009) Children, Schools and Families CommitteeSeventh Report. Training of children and families social workers. London House of Commons

Hawkins, P. and Shohet, R. (1989) Supervision in the Helping Professions. An Individual, group and organisational approach. Milton Keynes: Open

43 J. of Practice Teaching \& Learning 10(1) 2010, pp.27-44. DOI: 10.1921/ 146066910X570276. @ w\&bb 
University Press

Kadushin, A. (1992) What's wrong what's right with social work supervision? The Clinical Supervisior 10, 3-19

Kadushin, A. and Harkness, D. (2002) Supervision in Social Work. Chichester: Columbia University Press

Kolb, D. (1984) Experiential Learning as The Science of Learning Development. Englewood Cliffs, NJ: Prentice Hall

Konopka, G. (1963) Social Group Work: A Helping Process, Englewood Cliffs, NJ. Prentice Hall

Lord Laming ( 2009) The Protection of Children in England Report. London: TSO Lindsay, T. (2008) An investigation of group learning on practice placements.

The Higher Education Academy: Social Policy and Social Work (SWAP)

Mezirow, J. (1981) A critical theory adult learning and education. Adult Education 32,3-24

Mezirow, J. (2000) Learning as Transformation: Critical perspectives on a theory in progress, San Francisco: Jossey Bass

Preston-Shoot, M. (2007) Effective Groupwork, (2nd ed.) Basingstoke: Palgrave Ramsden, P. (1992) Learning to Teach in Higher Education. London: Routledge, Robson, C. (2000) Small scale evaluation. Principles and practice. London, Sage Sarantakos, S. (2005) Social Research (3rd ed.) Basingstoke: Palgrave Schon, D. (1987) Educating the Reflective Practitioner. San Francisco: Jossey- Bass Scottish Executive, (2004) Confidence in Practice Learning, Edinburgh, Scottish Executive

Scottish Executive (2006) Report of the 21st Century Social Work Review, Changing lives, Edinburgh: Scottish Executive

Walker, J., Crawford, K., and Parker, J. (2008) Practice Education in Social Work- A handbook for practice teachers, assessors and educators. Exeter: Learning Matters

Whittaker, A. (2009) Research Skills for Social Work. Exeter: Learning Matters 